\title{
A NOTE ON TERMS
}

In Rhodesia the codification of race by the state in various laws and proclamations existed in dialectical tension with its everyday uses across homes, workplaces and social clubs. Racial categories were predicated on the language of differentiation and dehumanisation and settlers used a number of derogatory terms to describe racial others. In this book I have opted to use the terms 'black' and 'African' interchangeably. I have also used 'white' and 'European' - the most common terms used by settlers to describe themselves. In using these terms myself, my intention is to convey as clearly as possible how people in the past understood race. In what follows, I hope I have made it clear as to where I am writing about representations of race in the past and where I am using descriptive or analytical terminology of my own.

Outside of southern Africa, 'Coloured' has been generally used as a derogatory slur for non-whites. Here, however, Coloured refers to a racial category that emerged in the late nineteenth-century western Cape and sought to group together a diverse range of persons of mixed African and European heritage, but also to a number of Asian persons, Cape slaves and the Khoisan population. In its Rhodesian expression, the term Coloured was used to describe some mixed-race persons whose very existence threatened colonial binaries. This argument, developed by Christopher Lee in Unreasonable Histories, is explored in Chapters 1 and 3 of this book. 